\title{
Grants to help women climb academic ladder
}

Rex Dalton, San Diego

Complaints that women still face discrimination in the upper reaches of US academia have been mounting in recent years. Now the National Science Foundation (NSF) whose own director, Rita Colwell, is the first woman ever to hold the position - plans to do something about it.

On 9 October the agency issued eight 'transformation grants', worth over \$3 million each, to help universities try out different approaches to tackle alleged iniquities in promotion practice on their campuses.

"There is not an institution in the country that couldn't use this kind of initiative," says Alice Hogan, head of the new NSF programme, which it calls Advance. "This is an investment," she says. "We are concerned about the health and viability of the American scientific and engineering workforce."

During the past 25 years, numerous reports have highlighted problems in hiring women faculty, providing them with tenure, and promoting them to positions such as that of department chair or dean. Many universities have undertaken individual plans to address deficiencies. But interviews with NSF grant winners show that such problems continue to persist.

Particle physicist Tricia Rankin, for example, who will run the Advance programme at the University of Colorado in Boulder, says: "Twenty years ago, I can remember being told the times are changing. Physics has certainly made improvements, like increasing the number of women physicist graduate students, but it is clear women are not making the breakthroughs anticipated.'

The Colorado Advance programme is designed to address campus-wide issues. It seeks "to improve the management and leadership skills of women so they can go up the academic ladder," says Rankin. "But if you really want to encourage change, you are better off modifying the behaviour of men, not women."

Susan Bryant, dean of biological sciences at the University of California, Irvine, who will lead the Advance programme there, says it will concentrate on making sure that women are adequately represented in candidate pools for faculty positions. "People have a tendency to forget either to be inclusive or to make a little extra effort," says Bryant.

At the University of Washington in Seattle, Denice Denton, dean of the school of engineering, will direct the programme. "I would like to see more women department chairs," she says. Women faculty have grown in number at universities such as Denton's, but few women chair departments. The University of Washington has no women chairs in science or engineering, for example.

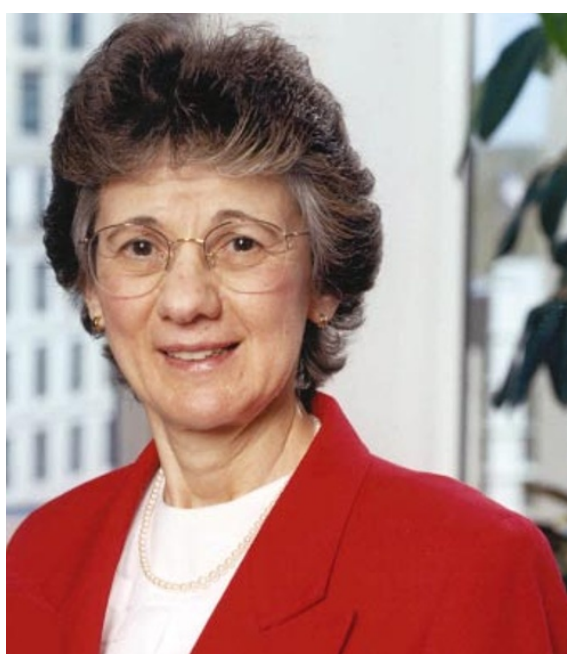

First lady: will Rita Colwell's success provide a blueprint for future women scientists?

The other Advance programme grants will go to the Georgia Institute of Technology in Atlanta, New Mexico State University at Las Cruces, the University of Puerto Rico, the University of Michigan and the University of Wisconsin at Madison.

The eight winners were selected from 76 universities that applied for the grants, and a ninth winner is expected to be announced shortly.

www.nsf.gov/advance

\section{Proposed scheme will scrutinize student supervisors}

\section{David Adam, London}

The pay may still be lousy and the hours at the bench long, but the lot of postgraduate students in British universities could be ready to take a turn for the better. Highereducation funding councils are set to introduce new standards and better training for supervisors of research degrees.

Poor supervision is often cited by research students as a problem in British universities. Last year, a review of research policy and funding by the Higher Education Funding Council for England (HEFCE), the government body that distributes teaching and infrastructure funding to English universities, stated that new standards are needed for scientists who act as supervisors. The Quality Assurance Agency for Higher Education, a watchdog body, has also called for better supervisor training.

Some universities and funding agencies already have guidelines in place, but no formal qualifications are required for supervising graduate students. In a move to fill this gap, the Biotechnology and
Biological Sciences Research Council (BBSRC), a life-sciences funding agency, last week announced a new national training and accreditation scheme for them.

The BBSRC scheme has already been piloted at the Institute for Animal Health in Pirbright, Surrey. Supervisors who applied for the qualification were assessed to

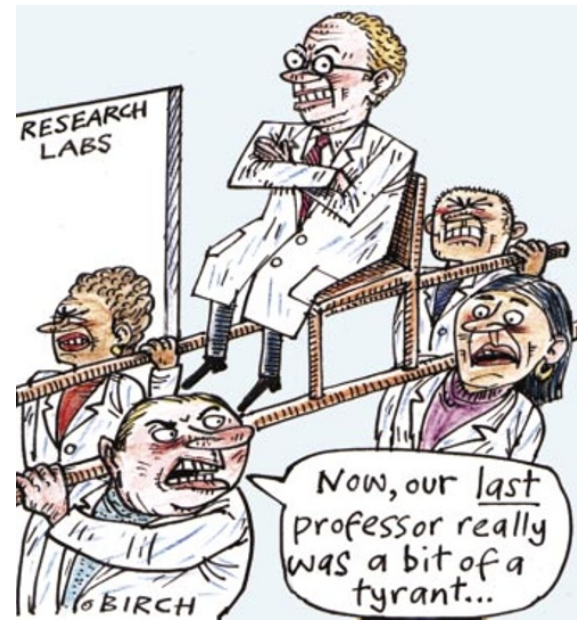

determine their ability to plan research projects and to check on student progress. The institute has now made the qualification mandatory for all staff who supervise students.

"Of course there have been bad supervisors in the past but we have to recognize that the entire environment is changing," says Peter Mertens, senior academic tutor at the institute. "It's becoming faster, more competitive and more difficult, and we have to make sure the system is up to that."

The HEFCE, meanwhile, is planning to follow up its report with new standards for supervisors, which it hopes to put in place by 2003 . The plans are at an early stage, but John Rushforth, head of research policy at the council, says that universities or departments whose staff fail to measure up will lose money. "If it all works as we envisage, then if you don't meet the standards, you don't get the funding," he says. The BBSRC says that its scheme is voluntary, however, and that there are no plans to link it to funding. 